\title{
Estimations of erosion fluxes, material deposition and tritium retention in the divertor of ITER
}

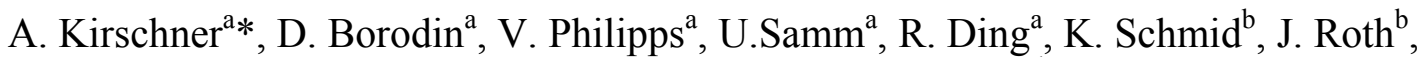 \\ A. Kukushkin ${ }^{\text {c }}$, G. Federici ${ }^{\mathrm{c}}$, A. Loarte ${ }^{\mathrm{d}}$ \\ ${ }^{a}$ Institut für Energieforschung - Plasmaphysik, Forschungszentrum Jülich, Association EURATOM- \\ FZJ, Trilateral Euregio Cluster, D-52425 Jülich, Germany \\ ${ }^{b}$ Max-Planck-Institut für Plasmaphysik, EURATOM Association, D-85748 Garching, Germany \\ ${ }^{c}$ ITER JWS Garching Co Center, Boltzmannstr. 2, D-85748 Garching, Germany \\ ${ }^{d}$ European Fusion Development Agreement, Close Support Unit, D-85748 Garching, Germany
}

\begin{abstract}
Material mixing effects on erosion/deposition and tritium retention in ITER have been modelled with ERO. It is seen that target lifetime is much less critical than tritium retention. A long-term tritium retention rate of $\sim 9 \mathrm{mg} \mathrm{T} / \mathrm{s}$ is obtained, assuming constant beryllium concentration in the background plasma of $0.1 \%$ for outer and $1 \%$ for inner divertor. Retention in inner is about twice that in outer divertor. Using a TriDyn-based model for mixed layers instead of homogenous material mixing does change the detailed profiles of erosion and redeposition. However, overall tritium retention is almost unchanged. Also, profiles for the beryllium influx along the divertor plates calculated with DivImp have been used for the ERO modelling. The resulting beryllium flux on the targets decreases by factors of 25 (inner) and 55 (outer divertor) compared to constant concentrations used so far. First ERO calculations using these beryllium profiles indicate a reduction of overall tritium retention by a factor of $\sim 4$ (compared to constant beryllium concentrations as used before), mainly due to reduced beryllium deposition.
\end{abstract}


PACS: 52.40.Hf

JNM keywords: Plasma-Material Interaction, Fusion Reactor Materials

PSI-18 keywords: ERO code, ITER, Tritium retention, Erosion/deposition, Target life-time

*Corresponding author address: Institut für Energieforschung - Plasmaphysik,

Forschungszentrum Jülich GmbH, D-52425 Jülich, Germany

*Corresponding author E-Mail: a.kirschner@fz-juelich.de

Presenting author: Andreas Kirschner

Presenting author E-Mail: a.kirschner@,fz-juelich.de 


\section{Introduction}

Main factors determining the availability of long-pulse or steady-state machines are wall lifetime and long-term tritium retention, which will also determine largely the success of ITER [1]. ITER will - at least in its first operation phase - use a material mix of beryllium (main wall), tungsten (baffles) and carbon (divertor plates). Estimations of tritium retention and wall lifetime for ITER mainly bear on full-carbon machines. Modelling is needed to extrapolate from present machines and in particular to account for effects arising from material mixing as expected in ITER. This work investigates the effect of material mixing on material erosion/deposition and tritium retention.

The three-dimensional Monte-Carlo code ERO [2] calculates erosion of wall elements and simulates transport of eroded impurities through a given background plasma. Impurities can be redeposited leading to build-up of deposition layers. ERO has been applied to various fusion experiments and successfully benchmarked with experimental findings, see e.g. [3]. Simulations of tritium retention and target lifetime for ITER have been published in [4], but at that time mixing of carbon with beryllium has been described with a simplified homogenous mixing model (HMM) assuming homogenous distribution of different species inside an interaction layer of given thickness. Within this model plasma-wall-interaction processes only take place inside the interaction layer. This simplified model cannot describe effects resulting from depth-dependent impurity concentrations. Therefore, ERO has been coupled with SDTrimSP, a version of TriDyn [5], which is a Monte-Carlo code calculating the transport of ions in matter using the binary collision approximation. Simulations of the built-up of carbon layers in TEXTOR with ERO-SDTrimSP did result in improved agreement with experimental observations compared to ERO-HMM simulations [6]. In chapter 2, ERO-SDTrimSP simulations for ITER will be compared with ERO-HMM calculations. Whereas in [4] a constant percent value for the beryllium divertor influx relative to the deuterium ion flux has 
been assumed, a more realistic spatial-dependent beryllium flux along the divertor plates resulting from DivImp [7] calculations has been used in chapter 3. Also, the influence of some variations of plasma temperature and density has been analysed. Resulting estimations of long-term tritium retention rates are presented.

Simulations within this presentation use ADAS [8] ionisation and recombination data (scd93, acd93) for atomic carbon and beryllium, whereas in [4] ionisation has been calculated with the Lotz formula [9]. ADAS ionisation data depend both on electron temperature and density, whereas Lotz formula only depends on electron temperature. Especially at low electron temperatures $(<$ about $10 \mathrm{eV})$ ionisation rate coefficients from ADAS are significantly larger than from Lotz (factor 10 to 100 ). At higher temperatures and densities below about $1 \cdot 10^{19} \mathrm{~m}^{-3}$ the ADAS data agree well with Lotz formula. As in [4], chemical erosion is described with a surface temperature, impact energy and impact flux dependent yield according to Roth [10]. Also, chemical erosion of redeposited carbon is assumed to be ten times larger than the one of substrate carbon [3]. Within ERO-SDTrimSP chemical erosion modelling considers different processes according to [10]: at the location where the deuterium is stopped erosion takes place with a yield $\mathrm{Y}_{\text {therm }}$ (reaction of thermalised deuterium particles enhanced by radiation damage) and at the surface with a yield $\mathrm{Y}_{\text {surf }}$ due to ion-induced desorption of hydrocarbons. A possible reduction of chemical erosion due to beryllium-carbide formation is not yet included in the modelling. The effective sticking of hydrocarbon species returning to the surface is assumed to be negligible.

\section{Erosion and deposition modelling: ERO-SDTrimSP compared to ERO-HMM}

The necessary background plasma parameters are taken from B2-Eirene [11]. Profiles along inner and outer divertor plates of electron and ion temperature, electron density, deuterium ion and atom flux can be found in [4]. The plasma parameters correspond to an (ELM- 
averaged) $\mathrm{H}$-mode discharge with $30 \%$ radiation. Profiles of surface temperature along the divertor plates [4] result from average operation conditions assuming a CFC target thickness of $10 \mathrm{~mm}$. For this modelling a constant percentage, $1 \%$ for inner and $0.1 \%$ for outer, influx of $\mathrm{Be}^{2+}$ ions into the divertor relative to the deuterium ion flux is assumed. Due to the lack of experimental data of beryllium influx into the divertor in machines with a beryllium main wall these numbers are somehow arbitrary. However, from existing machines it is known that there is an in-out asymmetry of scrape-off-layer flows leading to larger impurity flow to the inner divertor [12]. Also, the carbon concentration in the divertor flux of present machines with carbon main wall is typically in the percent range [13].

For ERO-HMM the thickness of the interaction layer is $40 \mathrm{~nm}$. ERO-SDTrimSP simulations use a total target thickness of $40 \mathrm{~nm}$, which is divided into 100 layers of $0.4 \mathrm{~mm}$ thickness. The simulations have been performed in steps of $\Delta t=0.05 \mathrm{~s}$ for a total time of (30s).

\subsection{Inner divertor}

Figure 1 shows the calculated time evolution of beryllium and carbon erosion and deposition rates. These rates result from integrating over the whole inner divertor target. The simulation starts with a pure carbon target, leading to zero beryllium erosion in the beginning. The beryllium deposition of about $2.3 \cdot 10^{22} \mathrm{Be} / \mathrm{s}$ at $\mathrm{t}=0.05 \mathrm{~s}$ is from the background flux and, with increasing exposure time, beryllium deposition increases due to redeposition of sputtered beryllium in addition to background deposition. The amount of redeposited beryllium is almost close to $100 \%$ relative to the amount of beryllium erosion (for ERO-HMM and EROSDTrimSP). This is mainly a result of ionisation rate coefficients from the ADAS database, which yield ionisation of sputtered beryllium atoms even at the lowest electron temperatures. The friction force then transports the ionised Be effectively back to the surface. As can be seen, after 30s almost steady-state is reached with constant erosion and deposition rates in both simulations. However, the erosion rate from ERO-SDTrimSP is about a factor of 1.8 
smaller than from ERO-HMM $\left(4.7 \cdot 10^{21}\right.$ and $8.4 \cdot 10^{21} \mathrm{Be} / \mathrm{s}$ respectively). Beryllium with higher energies from the background plasma penetrates deeper into the surface, which leads to a reduced sputtering of Be from the surface in SDTrimSP compared to HMM. Moreover, it has to be noted that in contrast to ERO-HMM the sputter yields in ERO-SDTrimSP at electron temperatures smaller than about $2 \mathrm{eV}$ (for the inner divertor this is the case at distances from the strike point smaller than $0.18 \mathrm{~m}$ ) are almost zero.

The right part of figure 1 shows the temporal evolution of the surface-integrated carbon erosion, including physical sputtering and chemical erosion of substrate carbon and redeposited carbon. Similar to beryllium, eroded carbon particles are redeposited also with a high probability, but reaching only about $98 \%$. The remaining $\sim 2 \%$ of eroded carbon particles escape from the local recycling process and move to the direction of the dome. Within the first 10s of exposure the carbon erosion rate from ERO-SDTrimSP is significantly larger than that of ERO-HMM. ERO-SDTrimSP takes into account depth-resolved deposition of particles. Thus, eroded carbon particles (with low energy) are redeposited near the surface and are resputtered more effectively. However, carbon erosion rate in steady-state calculated from ERO-SDTrimSP is similar to ERO-HMM $\left(1.2 \cdot 10^{21}\right.$ and $1.6 \cdot 10^{21}$ carbon particles/s, respectively). One reason for this is that in case of ERO-SDTrimSP a larger surface area on the target plate is covered with an almost pure beryllium layer. Also, reduction of carbon substrate erosion due to beryllium co-deposition is more effective in ERO-SDTrimSP than in ERO-HMM (again due to depth-resolved deposition profiles of beryllium). This results in smaller carbon substrate erosion (factor $\sim 4$ ) during the whole exposure time and finally to a smaller reservoir of redeposited carbon.

Figure 2 shows simulated steady-state concentration profiles of carbon substrate (c), redeposited carbon (cr) and beryllium (be) along the inner target from ERO-SDTrimSP and ERO-HMM. In case of ERO-SDTrimSP particle concentrations are integrated over all 100 
layers, in ERO-HMM the concentrations are given inside the interaction layer. Negative distances along the target correspond to private flux region (PFR), positive ones to scrape-off layer (SOL). With ERO-SDTrimSP only very small concentrations of redeposited carbon appear right to the strike point at around $0.1 \mathrm{~m}$ and in the far SOL, whereas ERO-HMM yields a significant concentration of redeposited carbon in an area between 0.2 and $0.6 \mathrm{~m}$ and also in the PFR.

Figure 3 shows a depth profile from ERO-SDTrimSP at $\mathrm{d}=0.55 \mathrm{~m}$ (net-erosion area). There is a small concentration of redeposited carbon very near to the surface but a relatively high beryllium concentration (up to 0.8). Also, the carbon substrate concentration near the surface of $0.2-0.4$ is much smaller than the integrated value of $\sim 0.9$, figure 2 . This explains the reduced overall carbon erosion in steady- state compared to ERO-HMM. Further depth profiles in figure 3 illustrate situations in the PFR $(d=-0.15 \mathrm{~m})$ and at a net-deposition zone with full beryllium coverage $(\mathrm{d}=0.13 \mathrm{~m})$ and thus zero carbon substrate concentration. The latter one shows the built-up of a mixed layer, mainly consisting of beryllium but with inclusion of a small, constant (in depth) amount of redeposited carbon.

Profiles of net-deposition/erosion rates including beryllium, substrate carbon and redeposited carbon are similar for ERO-SDTrimSP and ERO-HMM. Net-erosion zones occur for distances at the target $\mathrm{d}>\sim 0.5 \mathrm{~m}$ in case of ERO-SDTrimSP and $\mathrm{d}>\sim 0.47 \mathrm{~m}$ in case of EROHMM. Maximum net-erosion rates are about $3 \cdot 10^{19}$ particles $/ \mathrm{m}^{2} \mathrm{~s}$ for ERO-SDTrimSP and about $4 \cdot 10^{19}$ particles $/ \mathrm{m}^{2} \mathrm{~s}$ for ERO-HMM. Maximum net-deposition rates appear at $\mathrm{d} \sim$ $0.05 \mathrm{~m}$ with about $4.5 \cdot 10^{21}$ particles $/ \mathrm{m}^{2} \mathrm{~s}$ for both simulations.

\subsection{Outer divertor}

According to observed asymmetries in impurity fluxes of existing machines [12], the beryllium flux into the outer divertor has been reduced compared to inner one $(0.1 \%$ vs. $1 \%)$. Similar to the inner divertor, redeposition of eroded carbon and beryllium is high (Be: $\sim 100 \%$, 
carbon: $\sim 99 \%$ ). As discussed above, resulting from the depth-resolved impurity deposition, ERO-SDTrimSP leads to smaller beryllium erosion and larger erosion of redeposited carbon compared to ERO-HMM. However, due to smaller beryllium influx, areas of full beryllium coverage are smaller: in case of ERO-SDTrimSP it reaches from -0.03 to $0.07 \mathrm{~m}$ and in case of ERO-HMM from -0.03 to about $0.02 \mathrm{~m}$. The resulting surface-integrated erosion rates in steady-state at the outer divertor for beryllium are $5 \cdot 10^{21} \mathrm{Be} / \mathrm{s}$ (ERO-SDTrimSP) and $2.4 \cdot 10^{22}$ $\mathrm{Be} / \mathrm{s}$ (ERO-HMM) and for carbon (substrate plus redeposited) $6 \cdot 10^{22} \mathrm{C} / \mathrm{s}$ (ERO-SDTrimSP) and $3.5 \cdot 10^{22} \mathrm{C} / \mathrm{s}$ (ERO-HMM). Thus, the outer divertor shows 1.7 times larger carbon erosion with ERO-SDTrimSP and 5 times smaller beryllium erosion rates with ERO-SDTrimSP compared to ERO-HMM.

The overall net-deposition/erosion (including beryllium, substrate and redeposited carbon) along the outer target shows similar profiles from ERO-SDTrimSP and ERO-HMM. Neterosion zones appear in the far PFR and SOL with a maximum net-erosion rate (in the SOL) of about $1 \cdot 10^{20}$ particles $/ \mathrm{m}^{2} \mathrm{~s}(\sim 1 \mathrm{~nm} / \mathrm{s})$. Maximum net-deposition occurs at $\mathrm{d} \sim 0.05 \mathrm{~m}$ in the SOL with about $1.1 \cdot 10^{21}$ particles $/ \mathrm{m}^{2} \mathrm{~s}$.

\section{Erosion and deposition modelling with ERO-HMM: parameter variations}

Detailed discussion of the influence of parameter variations is out of the scope of this contribution. Here merely conclusions concerning surface-integrated erosion and deposition rates are drawn.

\subsection{Location-dependent beryllium influx}

DivImp [7] calculations show beryllium flux concentrations depending on target position. Figure 4 presents the beryllium fluxes for the inner and outer divertor in comparison to the assumptions used above. For the inner divertor the surface-integrated beryllium flux to the 
target is about 25 times smaller compared to the assumption of $1 \%$, for the outer divertor 55 times smaller compared to the assumption of $0.1 \%$ Be influx.

ERO-HMM calculations have been done for the inner divertor with a total exposure time of 100 s, after which steady-state is almost reached. Steady-state erosion rate for carbon increases by a factor of $\sim 2$, while the beryllium erosion slightly decreases compared to the previous simulations with $1 \%$ Be. Beryllium, which is first deposited in the far SOL regions of the target can be re-eroded and transported into the direction of the PFR where the background beryllium influx is small. As a result, an extended area of almost full beryllium coverage can evolve in the SOL, although with smaller beryllium concentration in the interaction layer. However, close to the strike point location the carbon substrate erosion cannot be reduced significantly due to the too small beryllium influx at this region. Steady-state beryllium netdeposition rate decreases by a factor of $\sim 25$ (according to the change of the background influx), carbon net-deposition rate on the target is almost unchanged. Remote carbon deposition increases significantly (factor $\sim 3$ ).

Simulations for the outer divertor with the Be-influx profile from DivImp have been done for 80s exposure time. Due to the very small beryllium influx, steady-state is not yet reached. The results obtained so far indicate a beryllium erosion, which is ten times smaller and a more than two times larger carbon erosion compared to the above calculations assuming $0.1 \% \mathrm{Be}$ influx. The beryllium net-deposition rate decreases by a factor of 55, carbon net-deposition on the target does not change significantly. Again, remote carbon deposition increases significantly (factor $\sim 3$ ).

\subsection{Erosion and deposition modelling: variations of plasma temperature and density}

For the outer divertor the following plasma parameter variations have been performed: $(1.4 \cdot \mathrm{n}, \mathrm{T}),(\mathrm{n}, 2 \cdot \mathrm{T})$ and $(2 \cdot \mathrm{T}, 0.71 \cdot \mathrm{n})$ with the combination $(\mathrm{n}, \mathrm{T})$ corresponding to the parameters used so far. The parameter sets $(1.4 \cdot \mathrm{n}, \mathrm{T})$ and $(\mathrm{n}, 2 \cdot \mathrm{T})$ result in 1.4 times increased ion fluxes, 
whereas with $(2 \cdot T, 0.71 \cdot n)$ the fluxes remain unchanged. All parameter variations lead to increased Be steady-state erosion fluxes with the highest erosion using $(2 \mathrm{~T}, \mathrm{n})$ - about a factor of three larger than with $(n, T)$. However, beryllium redeposition of eroded atoms is almost $100 \%$ for all simulations, therefore beryllium net deposition flux corresponds to the background flux and thus only varies by a factor of 1.4 within the parameter variations. Carbon erosion in steady-state differs by a factor of maximal 2, again with the largest fluxes using doubled electron temperature. Net carbon deposition rates behave similar to beryllium, i.e. maximal a difference of a factor of $\sim 1.4$. Significant difference is seen in the beryllium concentration profiles. With double temperature almost no beryllium is deposited in the far SOL due to increased sputtering.

\section{Summary}

The steady-state net-deposition rates for carbon and beryllium resulting from the modelling with constant Be influxes of $1 \%$ (inner) and $0.1 \%$ (outer) are summarised in table 1.a and 1.b. Net-deposition on remote areas results from the difference of erosion and local redeposition rates on the target. Long-term tritium retention rates have been estimated assuming constant $\mathrm{T} / \mathrm{C}$ and $\mathrm{T} / \mathrm{Be}$ fractions in deposited layers [4], see table. Tritium retention rates from EROHMM and ERO-SDTrimSP do not differ significantly. In the inner divertor carbon deposition rates on the target with ERO-SDTrimSP are smaller than with ERO-HMM due to better Beprotection and thus reduced C-substrate erosion. However, main T-retention occurs in beryllium layers, which is the same in both type of calculations. In the outer divertor, assuming a smaller but constant Be influx, ERO-SDTrimSP and ERO-HMM yield similar carbon deposition rates on the target. Retention in inner is about a factor of $2-3$ larger than in outer divertor. The obtained retention rate of $\sim 9 \mathrm{mg} \mathrm{T} / \mathrm{s}$ (inner plus outer divertor) results in 200 shots (@ 400s) before the T limit of 700g is reached. 
First simulations with Be fluxes based on DivImp indicate a reduced $\mathrm{T}$ retention in $\mathrm{Be}$ deposits but simultaneously an increased carbon erosion and thus codeposition with $\mathrm{T}$. However, the overall retention is decreased by about a factor of about 4 .

\section{Acknowledgements}

This work has been carried out under the EFDA task TW6-TPP-ERITERA and the European Task Force for Plasma Wall Interaction.

\section{References}

[1] Progress in the ITER Physics Basis, Nucl. Fus. 47 (2007)

[2] A. Kirschner et al., Nucl. Fus. Vol. 40, No. 5 (2000) 989

[3] A. Kirschner et al., J. Nucl. Mat. 328 (2004) 62

[4] A. Kirschner et al., J. Nucl. Mat. 363-365 (2007) 91

[5] W. Möller and W. Eckstein, Comput. Phys. Commun., 51 (1988) 355

[6] S. Droste et al., Plasma Phys. Control. Fusion 50 (2008) 015006

[7] P.C. Stangeby and J.D. Elder, J. Nucl. Mat. 196-198 (1992) 258

[8] H. P. Summers, ADAS users manual, JET-IR 06 (1994)

[9] W. Lotz, Z. Physik 216 (1968), 241

[10] J. Roth et al., J. Nucl. Mat. 337-339 (2005) 970

[11] G. Federici et al., J. Nucl. Mat. 313-316 (2003) 11

[12] G.F. Matthews, J. Nucl. Mat. 337-339 (2005) 1

[13] J.P. Coad et al., J. Nucl. Mat. 290-293 (2001) 224 


\section{Figure captions}

\section{Figure 1}

Temporal evolution of surface-integrated erosion and deposition rates of beryllium (left) and carbon (right) from ERO-SDTrimSP and ERO-HMM for the inner divertor. Gross-erosion and deposition carbon rates include substrate and redeposited carbon, net-deposition carbon rates only include redeposited carbon.

\section{Figure 2}

Steady-state concentration profiles along the inner target from ERO-SDTrimSP (left) and ERO-HMM (right).

\section{Figure 3}

ERO-SDTrimSP depth profiles after 30s at three locations on inner target.

\section{Figure 4}

Be influxes along inner and outer target from DivImp calculation ("Profile") compared to assumption of constant percentage ratio (“Const”) of $1 \%$ for inner and $0.1 \%$ for outer divertor. 


\section{Table 1}

Estimated carbon and beryllium deposition and tritium retention rates.

\begin{tabular}{|c|c|c|c|c|c|}
\hline \multirow[b]{2}{*}{$\begin{array}{l}\text { a) inner } \\
\text { divertor }\end{array}$} & \multicolumn{2}{|c|}{ carbon layers } & \multicolumn{2}{|c|}{ beryllium layers } & \multirow[b]{2}{*}{$\Sigma$} \\
\hline & $\begin{array}{c}\text { on target } \\
(\mathrm{T} / \mathrm{C}=\mathbf{0 . 0 5})\end{array}$ & $\begin{array}{c}\text { remote } \\
(T / C=0.5)\end{array}$ & $\begin{array}{c}\text { on target } \\
(\mathrm{T} / \mathrm{Be}=0.05)\end{array}$ & $\begin{array}{c}\text { remote } \\
(\mathrm{T} / \mathrm{Be}=0.05)\end{array}$ & \\
\hline \multirow{2}{*}{ НММ } & $8.0 \mathrm{e} 19 \mathrm{C} / \mathrm{s}$ & $4.5 \mathrm{e} 19 \mathrm{C} / \mathrm{s}$ & $2.4 \mathrm{e} 22 \mathrm{Be} / \mathrm{s}$ & $5.0 \mathrm{e} 20 \mathrm{Be} / \mathrm{s}$ & \\
\hline & $0.02 \mathrm{mg} \mathrm{T} / \mathrm{s}$ & $0.1 \mathrm{mg} \mathrm{T} / \mathrm{s}$ & $6 \mathrm{mg} \mathrm{T} / \mathrm{s}$ & $0.1 \mathrm{mg} \mathrm{T} / \mathrm{s}$ & $6.2 \mathrm{mg} \mathrm{T} / \mathrm{s}$ \\
\hline \multirow{2}{*}{ TRIM } & $2.0 \mathrm{e} 19 \mathrm{C} / \mathrm{s}$ & $2.1 \mathrm{e} 19 \mathrm{C} / \mathrm{s}$ & $2.45 \mathrm{e} 22 \mathrm{Be} / \mathrm{s}$ & $\sim 0 \mathrm{Be} / \mathrm{s}$ & \\
\hline & $0.005 \mathrm{mg} \mathrm{T} / \mathrm{s}$ & $0.05 \mathrm{mg} \mathrm{T} / \mathrm{s}$ & $6 \mathrm{mg} \mathrm{T} / \mathrm{s}$ & $\sim 0 \mathrm{mg} \mathrm{T} / \mathrm{s}$ & $6.1 \mathrm{mg} \mathrm{T} / \mathrm{s}$ \\
\hline
\end{tabular}

\begin{tabular}{|c|c|c|c|c|c|}
\hline \multirow[b]{2}{*}{$\begin{array}{l}\text { b) outer } \\
\text { divertor }\end{array}$} & \multicolumn{2}{|c|}{ carbon layers } & \multicolumn{2}{|c|}{ beryllium layers } & \multirow[b]{2}{*}{$\Sigma$} \\
\hline & $\begin{array}{c}\text { on target } \\
(T / C=0.05)\end{array}$ & $\begin{array}{c}\text { remote } \\
(T / C=0.5)\end{array}$ & $\begin{array}{c}\text { on target } \\
(\mathrm{T} / \mathrm{Be}=0.05)\end{array}$ & $\begin{array}{c}\text { remote } \\
(\mathrm{T} / \mathrm{Be}=0.05)\end{array}$ & \\
\hline \multirow{2}{*}{ НММ } & $8.7 \mathrm{e} 20 \mathrm{C} / \mathrm{s}$ & $3.0 \mathrm{e} 20 \mathrm{C} / \mathrm{s}$ & $3.84 \mathrm{e} 21 \mathrm{Be} / \mathrm{s}$ & $6.0 \mathrm{e} 19 \mathrm{Be} / \mathrm{s}$ & \\
\hline & $0.2 \mathrm{mg} \mathrm{T} / \mathrm{s}$ & $0.8 \mathrm{mg} \mathrm{T} / \mathrm{s}$ & $1.0 \mathrm{mg} \mathrm{T} / \mathrm{s}$ & $0.02 \mathrm{mg} \mathrm{T} / \mathrm{s}$ & $2 \mathrm{mg} \mathrm{T} / \mathrm{s}$ \\
\hline \multirow[t]{2}{*}{ TRIM } & $7.0 \mathrm{e} 20 \mathrm{C} / \mathrm{s}$ & 7.0e $20 \mathrm{C} / \mathrm{s}$ & $3.84 \mathrm{e} 21 \mathrm{Be} / \mathrm{s}$ & $6.0 \mathrm{e} 19 \mathrm{Be} / \mathrm{s}$ & \\
\hline & $0.2 \mathrm{mg} \mathrm{T} / \mathrm{s}$ & $1.8 \mathrm{mg} \mathrm{T} / \mathrm{s}$ & $1.0 \mathrm{mg} \mathrm{T} / \mathrm{s}$ & $0.02 \mathrm{mg} \mathrm{T} / \mathrm{s}$ & $3 \mathrm{mg} \mathrm{T} / \mathrm{s}$ \\
\hline
\end{tabular}


Figures

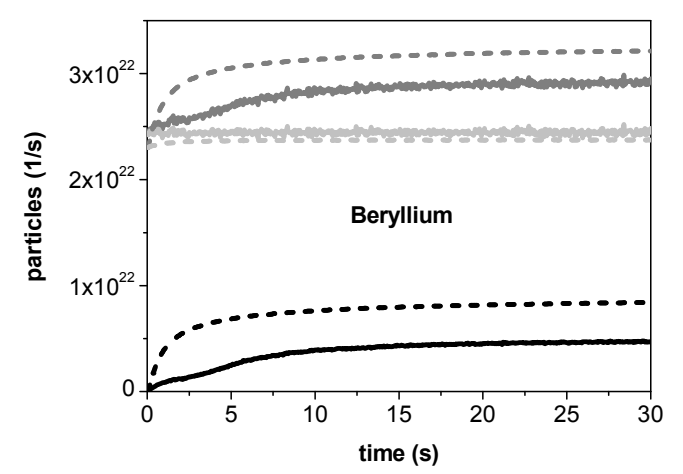

Figure 1

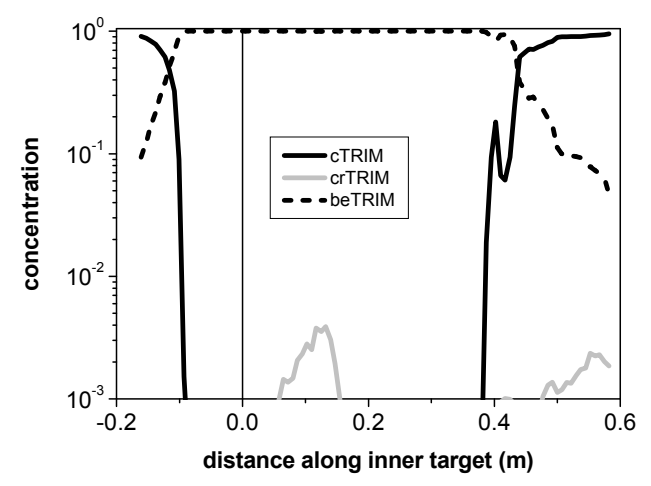

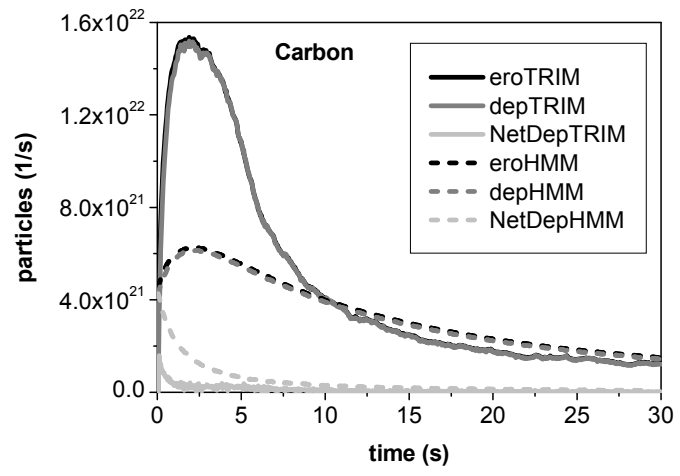

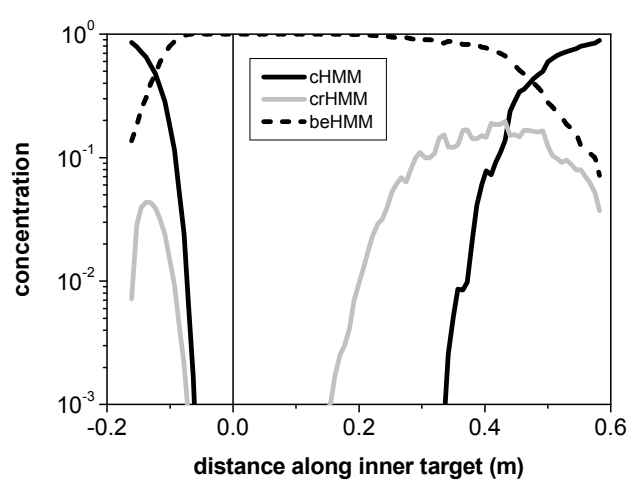

Figure 2 

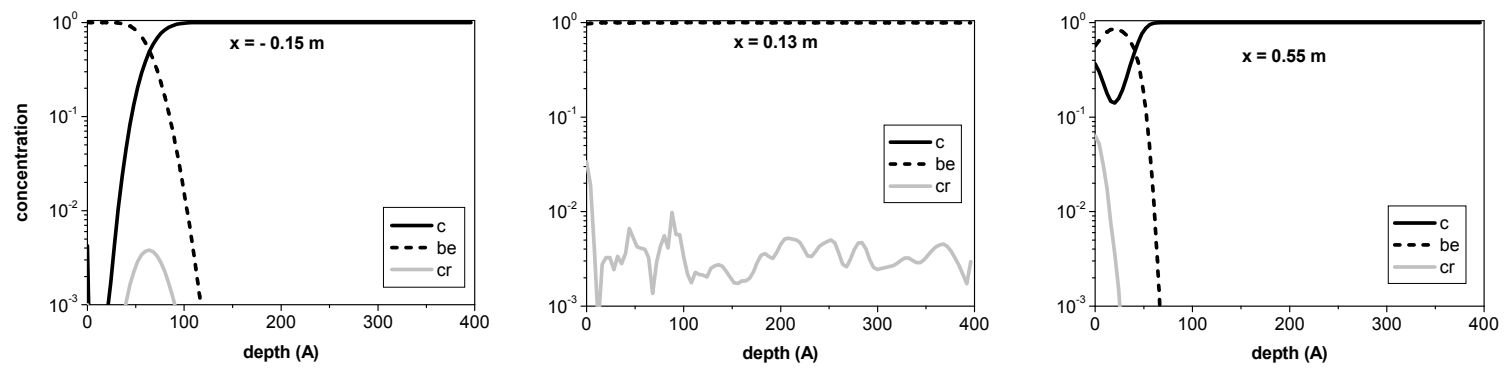

Figure 3

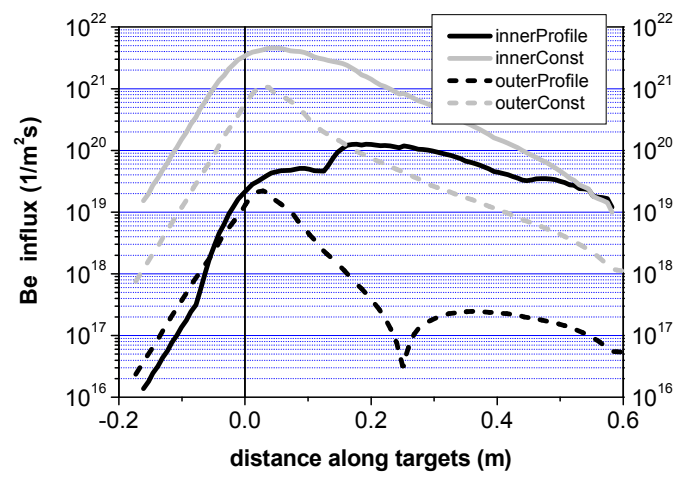

Figure 4 